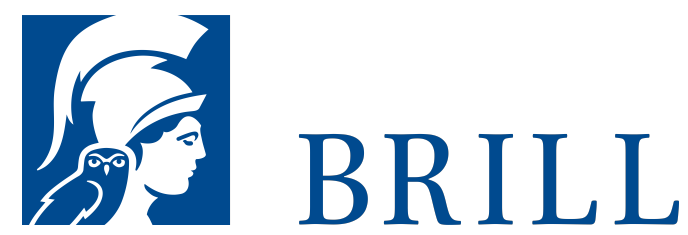

\title{
Literatur und Kontext
}

Untersuchungen zum Text-Kontext-Problem aus

textwissenschaftlicher Sicht

Author: Jan Borkowski

Die Interpretation literarischer Texte macht es erforderlich, Kontexte einzubeziehen. Kontexte spielen eine zentrale Rolle bei der Feststellung der Bedeutungen, die im Rahmen von Interpretationen typischerweise ermittelt werden. Die Relevanz von Kontexten für die wissenschaftliche Untersuchung von Literatur ist unstrittig, weswegen sie in der fachlichen Praxis in aller Regel berücksichtigt werden. Dieser Schein der Selbstverständlichkeit verschwindet jedoch sehr schnell, wenn man einfache Fragen stellt wie: Was genau heißt eigentlich »Kontext«? Wie hängen Text und Kontext zusammen? Wie sind Kontexte bei der Interpretation einzubeziehen? Solche Fragen konstituieren das »Text-Kontext-Problem«. Es handelt sich um ein textwissenschaftliches Grundlagenproblem, das trotz seiner Wichtigkeit bisher nicht die erforderliche Aufmerksamkeit erhalten hat. In dieser Arbeit wird es zum ersten Mal ausführlich und im Zusammenhang untersucht. Der literaturwissenschaftliche Grundbegriff »Kontext « wird in operationalisierbarer Weise expliziert, Überlegungen zu einem anschlussfähigen Text-Kontext-Modell werden angestellt und die allgemeine Methodik des Kontextualisierens in Grundzügen charakterisiert.

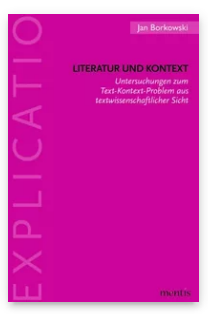

Pages: 322

Seiten

Language:

German

Subjects:

General,

Literature and

Cultural Studies

Publisher: Brill | mentis

Series:

Explicatio

E-Book (PDF)

Released online:

o1 Oct 2015

ISBN: 978-3-

95743-86o-7

List price

Paperback

Publication date:

o1 Oct 2015

ISBN: 978-3-

95743-045-8

List price 
For more information see brill.com

Order information: Order online at brill.com +44330 333 0049 | customerservices@brill.com Submission information: brill.com/authors

Titles published by Brill | Fink, Brill | mentis or Brill | Schöningh: +49(o)715413279216| brill@brocom.de 